\title{
Loss and recovery of leaf hydraulic conductance: Root pressure, embolism, and extra-xylary resistance
}

\author{
Troy W. Ocheltree ${ }^{1}$, Sean M. Gleason², Guo-Feng Jiang ${ }^{3,4}$, Kun-Fang Cao ${ }^{3,4}$
}

\begin{abstract}
${ }^{1}$ Department of Forest and Rangeland Stewardship, Colorado State University, Fort Collins, CO 80523-1472, USA; ${ }^{2}$ Water Management and Systems Research Unit, United States Department of Agriculture - Agricultural Research Service, Fort Collins, CO, USA; ${ }^{3}$ Guangxi Key Laboratory of Forest Ecology and Conservation, College of Forestry, Guangxi University, Nanning, Guangxi 530004, China; ${ }^{4}$ State Key Laboratory for Conservation and Utilization of Subtropical Agro-bioresources, Guangxi University, Nanning, Guangxi 530004, China
\end{abstract}

Corresponding author: Troy Ocheltree, troy.ocheltree@colostate.edu

Date of submission: 06/19/2019

Date of publication: $21 / 07 / 2020$

\begin{abstract}
Vascular networks in plant leaves must provide for the safe and efficient transport of water, nutrients, and energy; however, the conditions whereby these networks lose and regain conductive capacity are still poorly understood. We measured the loss and recovery of leaf hydraulic conductance $\left(K_{\text {leaf }}\right)$ in a tropical monocotyledon (Bambusa vulgaris) and dicotyledon species (Bauhinia blakeana) using the Rehydration Kinetics Method (RKM) and quantified the presence of embolized pixels from direct imaging of leaves. We found that both species lost ca $88 \%$ of their maximal $K_{\text {leaf }}$ (measured by RKM) before any embolism was detected in their conductive elements (via optical observation). This suggests that the majority of loss in $K_{\text {leaf, }}$ as measured with RKM, was associated with resistances other than that induced by embolism spread. Furthermore, embolism in B. vulgaris, a species known to generate root pressure, was reversed when rehydrated under positive pressure (120 kPa), but not under atmospheric pressure. In contrast, embolism was not reversed in $B$. blakeana under either elevated or atmospheric pressure. However, reductions in $K_{\text {leaf }}$ that was not associated with embolism was recovered by this species when rehydrated under atmospheric conditions, whereas $B$. vulgaris did not exhibit any recovery under the same conditions. We suggest that root pressure may be an adaptive mechanism allowing for the reversal of embolism and the recovery of extra-xylary conductance. The absence of embolism reversal in B. blakeana suggests that embolism may be permanent without neutral or positive xylem pressure, but that the recovery of extra-xylary conductance can be regained routinely in this species in the absence of root pressure.
\end{abstract}




\section{Introduction}

The inextricable link between carbon acquisition and water loss through stomatal pores is well recognized and studied (Cowan and Farquhar, 1977; Givnish, 1986; Willmer and Fricker, 1996). Considering this strong linkage, then, understanding the mechanisms that inhibit the supply of water to the leaves as soil moisture declines should be a priority, as should the mechanisms leading to the recovery of water supply after it has declined. Within leaves, reduced hydraulic conductance ( $K_{\text {leaf }}$ ) has been attributed to multiple mechanisms, which may operate together during water deficit (Johnson et al., 2012; Scoffoni et al., 2014; Trifiló et al., 2016). Loss of liquid-phase leaf hydraulic conductance may arise either from resistances originating in xylem conduits or in the tissues beyond the xylem (extraxylary). Increased resistance in the vasculature may result from either gas obstruction in the conduits from embolism formation (Zimmermann, 1983; Brodribb et al., 2016b) or the deformation of the conduits with decreasing water potentials (Zhang et al., 2016). Extra-xylary resistances are still poorly understood, but candidate mechanisms include aquaporin down-regulation (Cochard et al., 2007; Fischer \& Kaldenhoff, 2008), as well as the deformation of mesophyll cells and apoplast via leaf shrinkage (Scoffoni et al., 2014). The relative contributions of each of these extra-xylary components to Kleaf is not known for any species, much less how they might vary across species and habitats. Furthermore, it is not known if the proportion xylary and extra-xylary resistances remain similar during dehydration, or if the relative proportion may change with decreasing leaf water potential.

It is clear that once $K_{\text {leaf }}$ declines, its recovery is subject to the mechanism of its decline. If aquaporin downregulation is the primary or initial cause of $K_{\text {leaf }}$ decline, recovery could be expected to occur within hours or minutes (Cochard et al., 2007; Kim \& Steudle, 2009), or even within seconds (Fischer \& Kaldenhoff, 2008). Similarly, a recovery time of seconds or minutes might be expected in the case of vessel wall deformation/collapse, assuming that rebounding vessel walls do not exhibit marked hysteresis (Zhang et al., 2016). On the other hand, we might expect the recovery of embolized vessels to take hours or days (Salleo et al., 2004; Savi et al., 2016; Gleason et al., 2017; Brodersen et al., 2018), or perhaps not to occur at all if embolism formation is irreversible in situ (Cochard and Delzon, 2013; Choat et al., 2015).

Although the movement of water through a plant is generally driven by a free energy gradient, resulting in the water column being under 'tension', positive pressure in the root system has been well documented to occur in a range of species, and is often cited in regards to monocotyledons (Fisher et al., 1997; Enns et al., 2000; Cao et al., 2012a; Gleason et al., 2017), but also in dicotyledon trees (O’Leary, 1965; Hacke \& Sauter, 1996; Fisher et al., 1997), lianas (O'Leary, 1965; Fisher et al., 1997; Tibbetts and Ewers, 2000; Clearwater et al., 2007), and herbaceous species (Vaadia, 1960; Fisher et al., 1997; Stiller et al., 2003; De Swaef et al., 2013). Although the generating mechanism is yet to be identified (Pickard, 2003; Wegner, 2014), pressures range from ca 2 to $160 \mathrm{kPa}$ and are known to decrease precipitously with increasing canopy transpiration and decreasing soil water potential (Fisher et al., 1997; Gleason et al., 2017). Maximal root pressure has been shown to scale nearly proportionately with plant height across bamboo species, suggesting a refilling role, i.e., attaining positive xylem pressure in the face of gravity (Cao et al., 2012a), which has also been suggested in the case of maize and rice (Stiller et al., 2003; Gleason et al., 2017). However, a recent study suggests that in Vitis, root pressure may provide the water necessary for refilling, but the pressure gradient driving refilling is likely generated by osmotic accumulation within the vessels rather than root pressure, per 
se (Knipfer et al., 2016). Previous work on root pressure has not included measurements during the initial decline of $K_{\text {leaf }}$ nor its recovery, and so the linkage between these processes remains unclear.

To better understand the role of positive water potential in the recovery of $K_{\text {leaf }}$ we compared the loss and recovery of $K_{\text {leaf }}$ in one monocotyledon (Bambusa vulgaris Schrad. ex J.C. Wendl.) and one dicotyledon (Bauhinia blakeana Dunn) and assessed the occurrence of xylem refilling with and without simulated root pressure. We hypothesized that: 1) Cavitation events would begin in the lower vein orders (e.g., midribs) of both species and then progress to higher vein orders (e.g., minor veins) and 2) the accumulation of embolized xylem would drive losses in leaf hydraulic conductance. Based on the paradigm that root pressure in monocots allows refilling, we hypothesized that 3) embolized xylem of $B$. vulgaris would not refill without the aid of simulated root pressure, but that 4) embolized xylem of B. blakeana, which has minimal root pressure, would not be able to refill with or without simulated root pressure.

\section{Materials \& Methods}

\section{Plant Material}

To assess the role of root pressure in the refilling of embolized conduits we selected one species with known root pressure (B. vulgaris) and one species with minimal root pressure (B. blakeana). Root pressure in B. vulgaris has previously been assessed (Cao et al. 2012), and measurements of B. blakeana root pressure associated with this study showed minimal root pressure compared to similar sized plants of B. vulgaris (31.4 $\pm 1.8 \mathrm{kPa}$ compared to $\sim 120 \mathrm{kPa}$, data not shown). Plants selected for sampling were located adjacent to two small man-made lakes on the Guangxi University campus, Nanning, Guangxi Zhuang-Nationality Autonomous Region, China $\left(22.841^{\circ}, 108.286^{\circ} ; 84 \mathrm{~m}\right.$ asl). Details on the collection of leaf material are included in the appropriate sections below.

\section{Pressure-Volume curves}

Pressure volume curves were measured on leaves collected from five different individuals of $B$. blakeana and $B$. vulgaris to estimate turgor loss point ( $\left.\Psi_{\text {TLP }}\right)$, osmotic potential at full turgor $\left(\Psi_{\text {osm }}\right)$, modulus of elasticity $(\varepsilon)$, and leaf capacitance $\left(\mathrm{C}_{\text {leaf }}\right)$. Branches of each species were collected from sun-lit upper canopy positions (sampling height ranged from c. 3-5 $\mathrm{m}$ for B. vulgaris and 2-3 $\mathrm{m}$ for B. Blakeana) prior to sunrise on the morning of measurements. The total height of plants sampled ranged from c. 6-8 m among B. vulgaris individuals and c. 4-6 m among $B$. Blakeana individuals. For B. blakeana, branches were cut at least $100 \mathrm{~cm}$ long, with at least 6-10 leaves attached along the branch, immediately sealed in a plastic bag and transported back to the laboratory. For $B$. vulgaris, branches were cut with 3-5 branchlets attached, with each branchlet consisting of 7-9 leaf blades, immediately sealed in a plastic bag and transported back to the laboratory. In the lab, each branch was recut underwater, placed in a reservoir of water and allowed to rehydrate for $>2$ hours. One leaf was removed at a time and placed in either a plastic bag ( $B$. blakeana) or wrapped in paraffin (B. vulgaris) to slow dehydration. Leaves were kept in plastic bag/paraffin-wrap during the measurement of leaf water potential to prevent dehydration while in the chamber. Successive measurements of leaf water potential ( $\boldsymbol{\Psi}_{\text {leaf, }}$ Model 1505D, PMS Instruments, Albany, OR, USA) and leaf mass (0.0001 g, ML204T, Mettler Toledo) were made to generate pressure volume curves. Following the completion of the PV curve, leaf area 
was measured with a leaf area meter (LI-3000C, Li-Cor Biosciences, Lincoln, NE, USA) and then leaves were dried for $72 \mathrm{~h}$ and weighed.

\section{Leaf vulnerability to hydraulic failure using the Rehydration Kinetics Method (RKM)}

The vulnerability to hydraulic failure of leaves was estimated by developing vulnerability curves for B. blakeana and B. vulgaris using the Rehydration Kinetics Method (RKM; Brodribb and Holbrook, 2003). Branches were sampled during pre-dawn hours and allowed to rehydrate as described above (height, branch length, and number of branches). Thirty-nine individual leaves were used to build a vulnerability curve for B. blakeana and 27 small branchlets (ca 10$15 \mathrm{~cm}$ ), each with 7-9 leaves, were used to build a vulnerability curve for B. vulgaris. The response of leaf hydraulic conductance to decreasing $\Psi_{\text {leaf }}$ was measured for both species to develop vulnerability curves. Leaf hydraulic conductance $\left(K_{\text {leaf }}\right)$ was determined by measuring the change in $\Psi_{\text {leaf }}$ that occurred during rehydration and calculated after Brodribb and Holbrook (2003):

\section{Equation 1.}

$$
K_{\text {leaf }}=\frac{C_{\text {leaf }} \ln \left[\frac{\Psi_{0}}{\Psi_{f}}\right]}{t}
$$

where $\Psi_{0}$ and $\Psi_{\mathrm{f}}$ are the $\Psi_{\text {leaf }}$ before and after rehydration, respectively. ' $t$ ' is the duration of rehydration, and $C_{\text {leaf }}$ is the initial capacitance of the leaf estimated from the pressure volume curves described above. Prior to $K_{\text {leaf }}$ measurements the branchlets were set on the bench under an LED light source with a PAR of $\sim 1800 \mu \mathrm{mol} \mathrm{m}^{-2} \mathrm{~m}^{-1}$ (SP501-power, Senpro Mechanical \& Electrical Co. LTD, Shanghai), and leaves were kept under this light during measurements. $K_{\text {leaf }}$ was measured at a range of initial $\Psi_{\text {leaf }}$ values generated by allowing leaves to dehydrate for different lengths of time on the lab bench. The relationship between $\Psi_{\text {leaf }}$ and $K_{\text {leaf }}$ was fit with sigmoidal, logistic, exponential, and linear functions (Table 1) and then AIC values were used to select the function that best represented the decline in $K_{\text {leaf }}$ (Scoffoni et al., 2012; Ocheltree et al., 2016). For both the RKM method and the optical method, a single model was fit to the pooled data for each species, i.e. individual trees/branches/leaves were not fit with separate models. Using the selected function, we then calculated the maximum $K_{\text {leaf }}$ when leaves were fully hydrated $\left(K_{\text {sat }}\right)$ and the $\Psi_{\text {leaf }}$ when leaves lost $12 \%, 50 \%$, and $88 \%$ of $K_{\text {sat }}\left(P_{12}, P_{50}, P_{88}\right.$, respectively).

Table 1: Equations used to fit each function to the relationship between $K_{\text {leaf }}$ and $\Psi_{\text {leaf }}$.

\begin{tabular}{|c|c|}
\hline Function & Equation \\
\hline Linear & $K_{\text {leaf }}=m * \Psi_{\text {leaf }}+y_{0}$ \\
\hline Sigmoidal & $K_{\text {leaf }}=\frac{a}{1+e^{-\left(\frac{\Psi_{\text {leaf }}-x_{0}}{b}\right)}}$ \\
\hline Logistic & $K_{\text {leaf }}=\frac{a}{1+\left(\frac{\Psi_{\text {leaf }}}{x_{0}}\right)^{b}}$ \\
\hline Exponential & $K_{\text {leaf }}=y_{0}+a * e^{\left(b * \Psi_{\text {leaf }}\right)}$ \\
\hline
\end{tabular}


Recovery of $K_{\text {leaf }}$ using $R K M$

Branches were collected from the field and allowed to rehydrate as previously described. Branches were then allowed to dehydrate on the lab bench to achieve a range of $\Psi_{\text {leaf }}$ values. Two branchlets (ca $30 \mathrm{~cm}$ long) were cut from a single dehydrating branch. $\Psi_{\text {leaf }}$ and $K_{\text {leaf }}$ were then measured on two adjacent leaves taken from one of the branchlets, while the other branchlet (assumed to be at the same $\Psi_{\text {leaf }}$ ) was recut under water and allowed to rehydrate for 8-12 hours in a reservoir of DI $\mathrm{H}_{2} 0$. After the branchlet had rehydrated ( $\Psi_{\text {leaf }}$ had returned to near zero), it was taken from the reservoir and allowed to dehydrate once again for $\sim 5$ minutes underneath an LED light source and then $K_{\text {leaf }}$ was determined again as described above. This short dehydration time was required to generate a water potential gradient between $\Psi_{\text {leaf }}$ and the reservoir of water.

\section{Visualization of leaf embolism formation and repair using the optical method}

Leaves on rehydrated branches, collected from the field as described above (height, branch length, number of branches), were measured using the leaf 'optical' method (Brodribb et al., 2016b). Eight individual leaves were used to build an optical vulnerability curve for B. blakeana and seven individual leaves were used to build a vulnerability curve for $B$. vulgaris. Leaves were left attached to branches during both the dehydration and rehydration portions of the experiment. Branches were all $>100 \mathrm{~cm}$ in length. The cut end of rehydrated branches were transferred from a large DI water reservoir to $15 \mathrm{~mL}$ centrifuge tubes that were filled with water and sealed with paraffin to ensure the cut end of the branch remained under water during transfer to a high-resolution flatbed scanner (Epson Perfection V800, Epson Inc., Suwa, Japan). One fully-expanded leaf per branch, located towards the apex of the branch, was selected and placed on the scanner bed, sandwiched between two 4-mm thick plates of glass. This placement ensured that the leaf was at the proper focal length from the scanner bed, and also minimized transpiration from the leaf surface, such that $\Psi_{\text {leaf }}$ could be closely approximated by $\Psi_{\text {stem. }}$. Four leaves were placed on the scanner bed at the same time with the full length of the branch $(\sim 1.5 \mathrm{~m})$ attached and laid carefully alongside the scanner. For the dicot, B. blakeana, $\Psi_{\text {stem }}$ was measured continuously at 10 -min intervals using a stem psychrometer (model PSY1, ICT International, Armidale, NSW, Australia) placed on a stem that was closely adjacent to the leaves in the scanner and verified periodically (ca every two hours) by measuring $\Psi_{\text {leaf }}$ using a pressure chamber. The unique stem morphology of $B$. vulgaris prevented the use of the stem psychrometer, and so, more frequent $\Psi_{\text {leaf }}$ measurements (ca $~ 30$ min) were taken with the pressure chamber. Dehydration times varied markedly between the species. B. blakeana branches required c. 12-18 h to progress from fully hydrated to fully embolized, whereas B. vulgaris required c. 9-12 h. The time required to progress from the moment of first embolism occurrence to full embolization, ranged from 6-11 hours for B. blakeana and 5-7 h for B. vulgaris.

Dehydrated branches ( $K_{\text {leaf }} \sim 50 \%$ of maximal) were rehydrated under two treatment conditions: 1$)$ positive pressure ( 120 kPa), and 2) atmospheric pressure whilst still on the scanner to assess their capacity to reverse embolism. $120 \mathrm{kPa}$ was chosen to approximate the recorded root pressure in B. vulgaris (Cao et al., 2012a). For the atmospheric pressure treatment, whilst still on the scanner branches were re-cut underwater and sealed with paraffin in a $15 \mathrm{~mL}$ centrifuge tube filled with $\mathrm{DI} \mathrm{H}_{2} \mathrm{O}$ to allow rehydration. The elevation of the vial was kept at, or slightly below, the level of the scanned leaf during this process to minimize the chance of any positive pressure generated by 
the placement of the reservoir of water, although the capillary pressure due to vessel diameter could not be controlled. For positive pressure treatment, branches were re-cut underwater and sealed into water-filled tubing connected to a small pressure chamber. Pressure was maintained between 117 and $124 \mathrm{kPa}$ throughout the rehydration treatment. Scanning of the leaves continued during the rehydration treatment at 10 min intervals, as described above.

Leaves were scanned every 10 min using VueScan software (Hamrick Software, Sunny Isles Beach, Florida, USA). AutoIt freeware (Bennett, 1999) was used to automate the scanning. The VueScan settings were: mode $=$ 'transparency', media = 'slide film', bits = '8-bit gray', scan resolution $=$ '3200 dpi'. The scanned area (ie. the full area of the scanner bed) was divided into four quadrants so that each leaf could be assigned to an individual quadrant and scanned separately. For B. vulgaris, a $\sim 4 \mathrm{~cm}^{2}$ area of each leaf was scanned at high resolution (3200 dpi), whereas the larger leaves of $B$. blakeana allowed for a $\sim 16-\mathrm{cm}^{2}$ area to be scanned at high resolution. As the xylem became more embolized in both species, individual veins could be observed to darken, presumably from the liquid-togas phase change occurring in the vessels (Brodribb et al., 2016a,b). As such, the transmission of light through the leaf decreased during xylem embolization, and therefore, the fraction of dark-colored pixels increased in the scanned images. Changes in the fraction of dark-colored pixels were analyzed using 'ImageJ' analysis software (Schneider et al., 2012). For each leaf dry-down sequence, the threshold of the first image was adjusted such that the individual veins were represented by white pixels when converted to a binary image (an image consisting of only white or black pixels). The fraction of black pixels was recorded and this value was assumed equal to $100 \%$ xylem functioning. This threshold was then kept constant for each subsequent image in the sequence (all images taken from a single leaf as it dried down). As the xylem became more embolized, the images became darker and the recorded fraction of black pixels increased. Images were analyzed in this way until the xylem was completely embolized, which was taken as the point when no further meaningful change in either light transmission or the fraction of dark-colored pixels occurred between two subsequent images. The fraction of black pixels in the final image was assumed equal to $0 \%$ xylem functioning. The percent loss of functioning (as estimated via the fraction of black pixels present in each image) was then plotted against $\Psi_{\text {leaf }}$ to generate percent loss of 'conductance' curves. Although shrinkage and subsequent movement of the leaves on the scanner prevented automated analysis of our images, our fraction of black pixels should, in principle, be the same measurement of "cumulative area of cavitated xylem" described elsewhere (Brodribb et al. 2017). For B. vulgaris, $\Psi_{\text {leaf }}$ values were estimated for each scanned image (every 10 min) by plotting measured $\Psi_{\text {leaf }}$ values against time and then solving this equation for the time each image was taken. For B. blakeana, the recorded psychrometer data were used because these were taken on the same time interval as the images (10 min).

\section{Results}

\section{Pressure-volume analyses}

Parameters from the pressure volume curves (Table 2) provided several drought tolerant metrics and capacitance values used to calculate $K_{\text {leaf }}$. The turgor loss point ( $\left.\Psi_{\text {TLP }}\right)$ of the monocotyledon B. vulgaris was $-3.07 \mathrm{MPa}$, which was 1.94 MPa more negative than the woody dicotyledon B. blakeana. The difference in $\Psi_{\text {TLP }}$ was mirrored by differences in the osmotic potential ( $\left.\Psi_{\text {osm }}\right)$ between the two species; $\Psi_{\text {osm }}$ of $B$. vulgaris was 1.16 MPa more negative than B. blakeana. B. vulgaris also had a larger modulus of elasticity $(\varepsilon)$ than B. blakeana. Conversely, the leaf capacitance of B. blakeana was $\sim 4$ times greater than for B. vulgaris. 
Table 2: Parameters derived from pressure-volume curves created for the two species studied. Letters indicate significant differences between the two species at the $\mathrm{p}<0.05\left(^{*}\right)$ and $\mathrm{p}<0.001\left({ }^{* *}\right)$ significance levels.

\begin{tabular}{|l|l|l|}
\hline Parameter & Bauhinia blakeana & Bambusa vulgaris \\
\hline $\begin{array}{l}\Psi_{\text {TLP }} \\
(\mathrm{MPa})\end{array}$ & $-1.13 \pm 0.02^{\mathrm{a}^{* *}}$ & $-3.07 \pm 0.22^{\mathrm{b}^{* *}}$ \\
\hline $\begin{array}{l}\boldsymbol{\Psi}_{\text {osm }} \\
(\mathrm{MPa})\end{array}$ & $-1.01 \pm 0.03^{\mathrm{a}^{* *}}$ & $-2.67 \pm 0.26^{\mathrm{b}^{* *}}$ \\
\hline $\begin{array}{l}\varepsilon \\
(\mathrm{MPa})\end{array}$ & $23.6 \pm 6.00^{\mathrm{a}^{*}}$ & $179.70 \pm 75.31^{\mathrm{b}^{*}}$ \\
\hline $\begin{array}{l}C_{F T} \\
\left(\mathrm{mmol} \mathrm{m} \mathrm{MPa}^{-1}\right)\end{array}$ & $0.28 \pm 0.05^{\mathrm{a}}$ & $0.24 \pm 0.11^{\mathrm{a}}$ \\
\hline $\begin{array}{l}C_{T L P} \\
\left(\mathrm{mmol} \mathrm{m} \mathrm{MPa}^{-1}\right)\end{array}$ & $1.43 \pm 0.52^{\mathrm{a}^{*}}$ & $0.70 \pm 0.14^{\mathrm{b}^{*}}$ \\
\hline
\end{tabular}

\section{Loss and recovery of leaf conductance using RKM}

Sigmoidal functions provided the best fit to the RKM data for both species (Figure 1, grey symbols and dashed lines). B. vulgaris lost 12,50 , and $88 \%$ of its maximum leaf hydraulic conductance at leaf water potentials of $-0.6,-2.5$ and -4.3 MPa, respectively. B. blakeana lost the same percentage of hydraulic conductance at $\Psi_{\text {leaf }}$ values of $-2.4,-3.3$ and -4.6 MPa, respectively, but did maintain consistently positive $K_{\text {leaf }}$ down to $-4.0 \mathrm{MPa}$.

Figure 1: Loss and recovery of $K_{\text {leaf }}$ for $B$. blakeana (a) and B. vulgaris (b) following dehydration and rehydration as measured by RKM. Pairs of red and blue symbols (connected by solid lines) represent pairs of leaves on the same branch. Red symbols denote $K_{\text {leaf }}$ of dehydrated leaves and the blue symbols denote $K_{\text {leaf }}$ of leaves that had been rehydrated for 8-12 hours. Note that for B. blakeana leaves that were dehydrated to $\Psi_{\text {leaf }}<-3.5 \mathrm{MPa}$ did not recover, whereas, B. vulgaris did not exhibit any recovery of $K_{\text {leaf. }}$

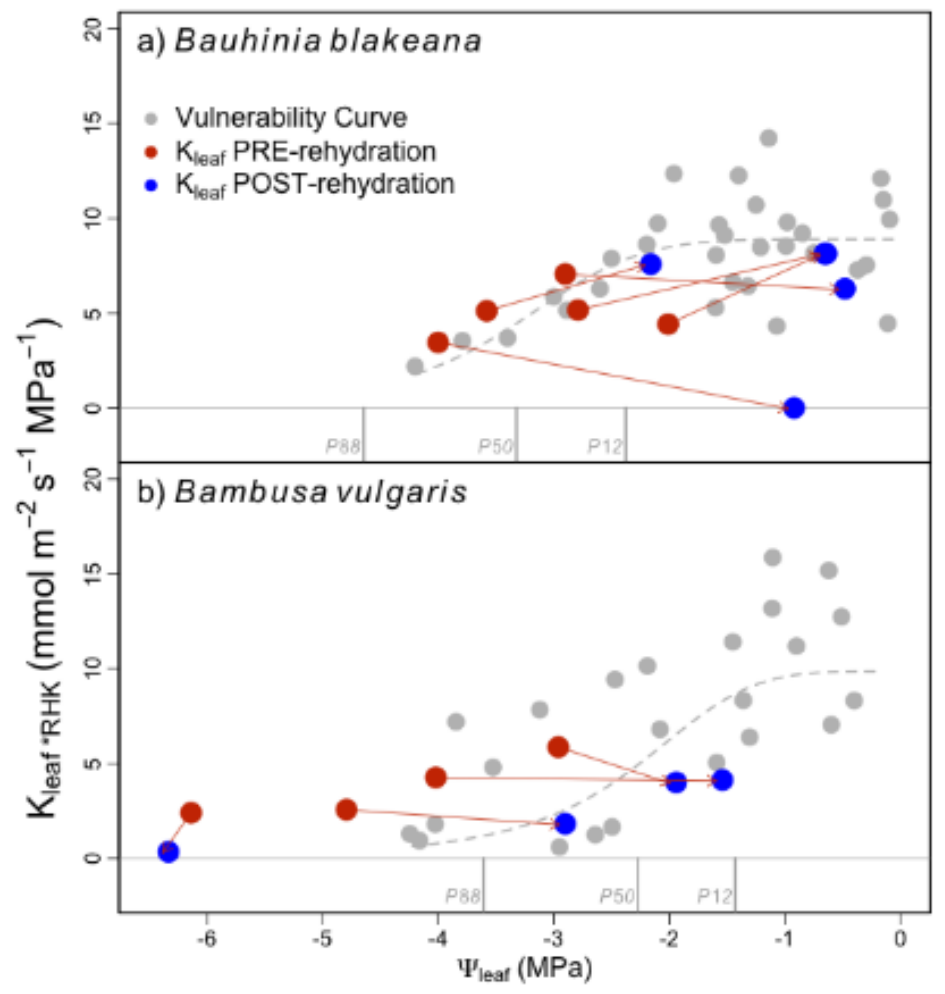

The recovery of $K_{\text {leaf }}$ following a dehydration/rehydration cycle differed between the two species. In Figure 1, the red symbols represent $K_{\text {leaf }}$ of dehydrated leaves, and the blue symbols represent $K_{\text {leaf }}$ of leaves from the same branches that were rehydrated for 8-12 hours. The arrows connecting the red and blue symbols are intended to help 
visualize the trajectory of recovery (or lack there-of) of leaves from the same branch. $K_{\text {leaf }}$ of the dicotyledon leaves investigated, B. blakeana, dehydrated down to -4 MPa recovered along the same fitted line (ie. no hysteresis) as the decline in $K_{\text {leaf }}\left(\right.$ Figure 1a). However, once leaves were dehydrated $<-4 \mathrm{MPa}, K_{\text {leaf }}$ did not recover but, rather, continued to decline during the rehydration treatment (Figure 1a) despite the leaf rehydrating (i.e., $\Psi_{\text {leaf }}$ became less negative). None of the leaves of B. vulgaris showed a recovery of $\mathrm{K}_{\text {leaf }}$ following rehydration (Figure $1 \mathrm{~b}$ ).

Figure 2: Leaf embolization curves during dehydration of $B$. blakeana and $B$. vulgaris using the

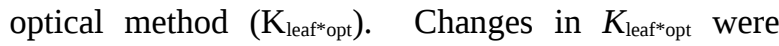
approximated from changes in the light transmission through leaves. Note that embolism in both species was not detected until $\Psi_{\text {leaf }}$ decline below the P88 values (estimated using RKM; Figure 1) for both species.

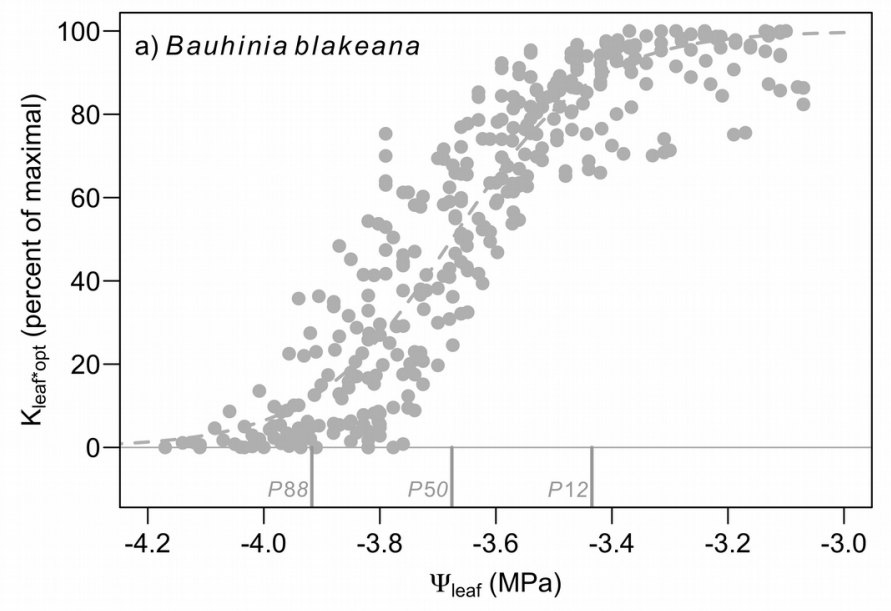

Estimated loss and recovery of leaf conductance using the optical method

Vulnerability curves constructed using data from the optical method were fit with sigmoidal models similar to the RKM results. B. blakeana, the dicotyledon species, exhibited less negative $P 12$, P50, and P88 values than B. vulgaris when compared using the optical method (Figure 2). However, in marked contrast to RKM, the optical method resulted in much lower (more negative) $P X$

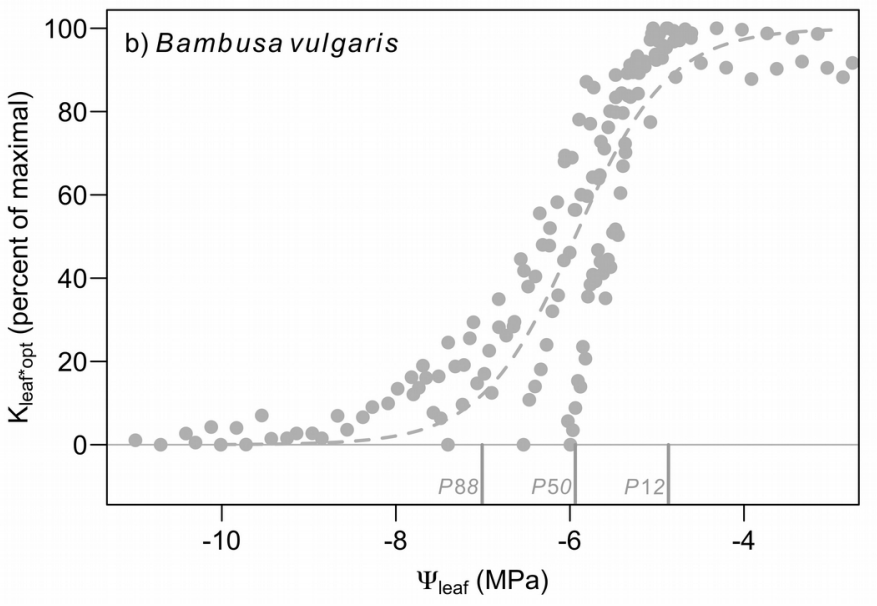
values for both species. Using the optical method, B. blakeana leaves exhibited very little embolism until $\boldsymbol{\Psi}_{\text {leaf }}$ values fell below ca -3.4 MPa (Figure 2a, Figure 3a), which is the point when this species lost $50 \%$ of its $K_{\text {leaf }}(-3.3 \mathrm{MPa})$. Similarly, markedly little embolism was observed in B. vulgaris until $\boldsymbol{\Psi}_{\text {leaf }}$ declined below -4.9 MPa (Figure 2b, Figure, $3 \mathrm{~b}$ ); $K_{\text {leaf }}$ was reduced by $88 \%$ of its maximum at $-4.3 \mathrm{MPa}$ in this species. Both species showed clear declines in $K_{\text {leaf }}$ by -3 MPa when analyzed using the RKM (Figure 1), but no embolized vessels were detected at this water potential, and so the optical method resulted in $P X$ values that were more negative than RKM (Figs $1 \& 2$ ). 


\section{Journal of

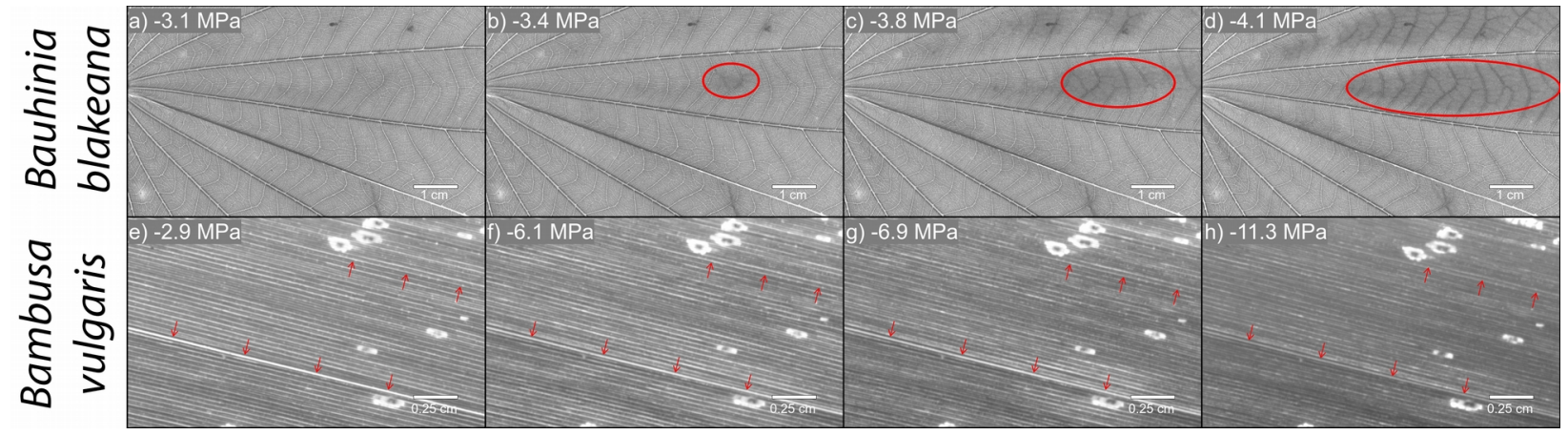

Figure 3: Example of an embolization sequences for B. blakeana $(\mathrm{a}-\mathrm{d})$ and B. vulgaris $(\mathrm{e}-\mathrm{h})$ using the optical method. The transition of veins from light colored pixels to dark colored pixels are interpreted as the liquid-to-gas phase change (i.e., embolism) in vessels. $\Psi_{\text {leaf }}(\mathrm{MPa})$ is given in the upper-left corner of each panel. Videos of the entire sequence have been supplied online (Ocheltree, 2017) as well as in the supplemental materials.

Embolism in B. blakeana began first in the higher vein orders and progressed to lower vein orders as water potential declined (Figure 3 a, b, c, d). Similarly, embolism in B. vulgaris began in vascular bundles closer to the leaf margins and progressed closer to the midrib as water potential declined (Figure $3 \mathrm{e}, \mathrm{f}, \mathrm{g}, \mathrm{h}$ ). Neither species exhibited refilling of embolized vessels (i.e., increased light transmission) when stems were re-cut and allowed to rehydrate under atmospheric pressure. Additionally, applying positive pressure to the stems of B. blakeana during rehydration did not result in refilling of embolized vessels, but did result in the discoloration (brown color development) of the lamina directly adjacent to the veins (Figure 4a-d, video link: https://www.youtube.com/watch?v=0xiCk_0rUaU). We speculate that this may indicate that the mesophyll cell membranes had ruptured, either during the dry-down or when positive pressure was applied. In the case of $B$. vulgaris, applying $120 \mathrm{kPa}$ of positive pressure did result in partial recovery (Figure 4e-h, video link: https://www.youtube.com/watch?v=pZbw4NVcoI0), particularly evident near the midrib, whereas veins closer to the leaf margins continued to embolize even after pressurizing the stem (Figure 3e-h).

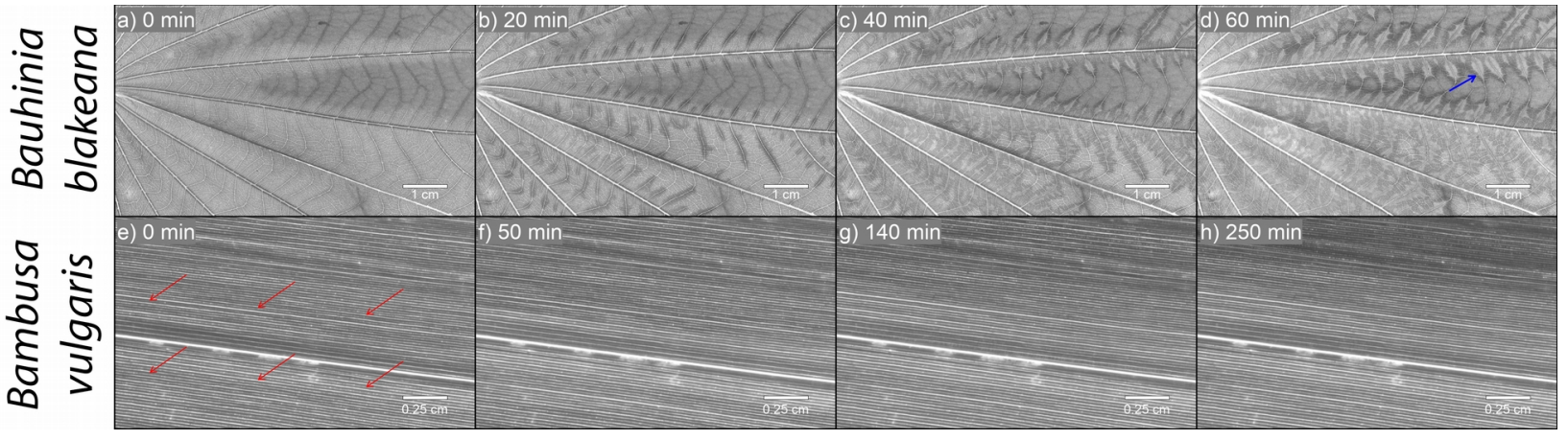

Figure 4: Example of a rehydration (120 kPa) sequence for B. blakeana $(\mathrm{a}-\mathrm{d})$ and B. vulgaris $(\mathrm{e}-\mathrm{h})$. Rehydration time is denoted in the upper-left corner of each image. Panel 'a' shows the leaf with darkened veins and lamina that developed during rehydration; panels ' 'c'-'d' show the continual darkening of the veins and lamina while water was forced through the vasculature without refilling. The blue arrow in panel ' $\mathrm{d}$ ' indicates where cytoplasm has been pushed through damaged membranes in $B$. blakeana leaves. The red arrows in panel 'e' denote the section of the leaf undergoing refilling, and thus becoming lighter. Note that the dark areas away from these arrows, and closer to leaf edges, continued to embolize during rehydration. Videos of the entire sequence have been supplied online (Ocheltree, 2017) as well as in the supplemental materials. 


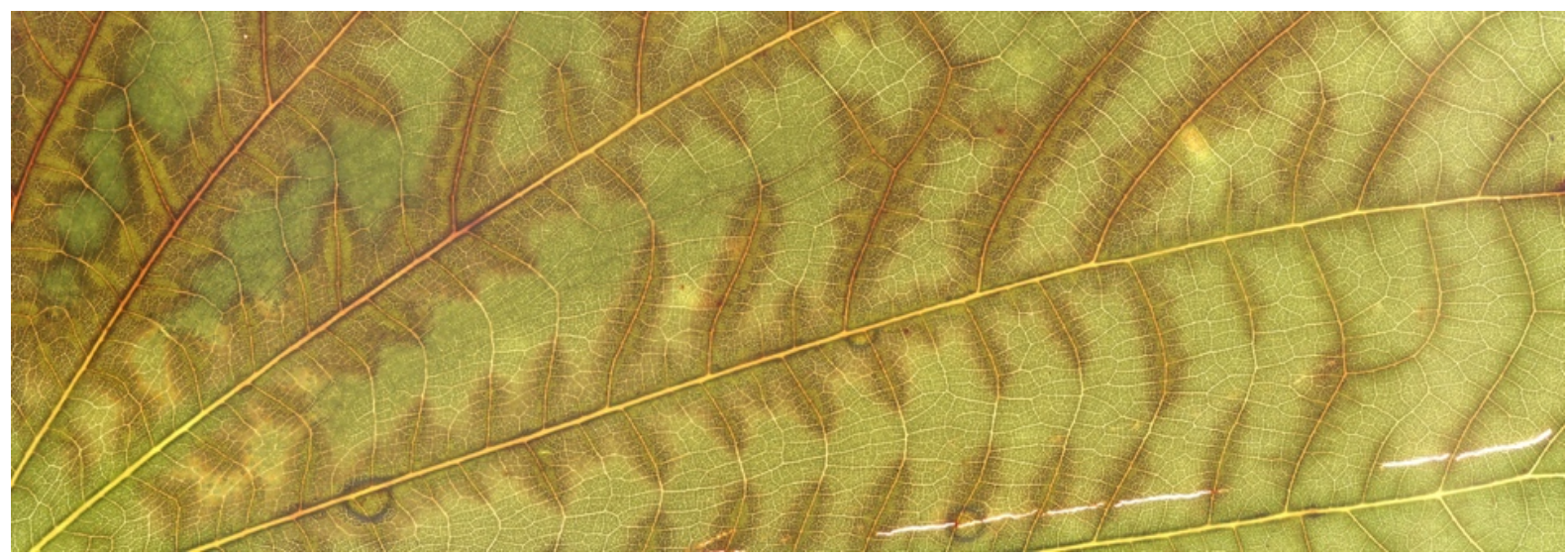

Figure 5: Section of a Bauhinia blakeana leaf that had been dehydrated followed by a positive-pressure treatment. After this treatment combination, leaves exhibited leaf lamina that appeared completely saturated and quickly turned brown in color. That saturation stopped at the point that embolisms had formed, such that it appeared that water could travel through xylem until it hit the point of embolisms and then the water 'leaked' from the vasculature. At the locations where water leaked out, the lamina and vein tissue turned brown in color, which we suspect is from the leakage of cell-contents due to membrane damage.

\section{Discussion}

\section{Possible mechanisms for the decline and recovery of $K_{\text {leaf }}$ using $R K M$}

We found that leaf hydraulic conductance $\left(K_{\text {leaf }}\right)$ of both species declined by $>50 \%$ (Figure 1 ) prior to the observation of any embolism formation (Figure 2). These results suggest that the initial decline in $K_{\text {leaf }}$ does not result from embolism formation in either Bauhinia blakeana or Bambusa vulgaris (Figs 1 \& 2), but is likely a result of declining conductance in extra-xylary tissues (Scoffoni et al., 2014; Trifiló et al., 2016) or vessel deformation/collapse (Cochard et al., 2004; Blackman et al., 2010; Zhang et al., 2016). These two mechanisms could potentially reduce $K_{\text {leaf }}$ independently of any gas obstruction in the conducting elements and would explain the large reduction in $K_{\text {leaf }}$ we observed prior to any embolism formation in the veins of these species. Although this data represents only two species, the species selected have very different anatomical traits and vastly different evolutionary histories.

Although the results from these species highlight the potential role of vessel collapse and extra-xylary conductance on declining $K_{\text {leaf }}$, the recovery of $K_{\text {leaf }}$ show markedly different results. If vessel collapse/deformation caused the initial decline in $K_{\text {leaf, }}$ we might expect a relatively rapid recovery of $K_{\text {leaf }}$ because it has been shown that the collapsed vessels in Quercus spp. recover their original shape within seconds to minutes following collapse (Zhang et al., 2016). Similarly, if the initial decline in $K_{\text {leaf }}$ was associated with aquaporin down-regulation in extra-xylary tissues, we might expect upregulation to occur within minutes to hours following rehydration (Cochard et al., 2007; Kim \& Steudle, 2009), although the signal to upregulate aquaporins during rehydration has not been studied in leaves. In this study, leaves were provided a recovery period of 8-12 h, which would likely have allowed the recovery of $K_{\text {leaf }}$ via both of these proposed mechanisms. When $\Psi_{\text {leaf }}$ stayed above -3.5 MPa, we did observe recovery of $K_{\text {leaf }}$ in $B$. blakeana leaves, although there were only 4 replicate leaves to which this condition applied. However, we observed no recovery in $B$. vulgaris for the 4 leaves we measured, highlighting the inability of $K_{\text {leat }}$ to recover in this species in the absence of root-pressure. This suggests that either the mechanism of conductance loss and/or the mechanism or 
signal to initiate conductance recovery differ between these two species, highlighting the need for additional research focused on the recovery of $K_{\text {leaf }}$ during leaf re-hydration. Although intriguing, we acknowledge the low replicates of $K_{\text {leaf }}$ recovery leave much uncertainty in the degree and thresholds of leaf recovery and encourage the measurement of this response in a much larger set of species.

To visualize the timing of $\mathrm{K}_{\text {leaf }}$ decline, embolism formation, and the point of stomatal closure, we combined the vulnerability curves from the RHK and optical method along with the turgor loss point of each species (Figure 6), which is typically correlated with the point of stomatal closure (Farrell et al., 2017). The stomata of B. blakeana leaves closed before any decline in $K_{\text {leaf }}$ and well before any embolism formation. B. vulgaris, on the other hand, maintained open stomates until $\Psi_{\text {leaf }}$ reached the same point of $~ 50 \%$ loss in $K_{\text {leaf }}$, but stomates closed well before any embolism formation. These results suggest stomata close in order to prevent embolism formation in both species, which agrees with other recent research on tree species (Creek et al., 2020). However, B. vulgaris operates with a more 'aggressive' strategy in that it continues water-use despite reductions in $K_{\text {leaf }}$. B. vulgaris may be able to maintain positive stomatal conductance despite losses of leaf hydraulic conductance because it can recover from these losses if positive pressure can be supplied, presumably from root tissue (Cao et al., 2012; Yang et al., 2012). B. blakeana, however, did not exhibit an ability to recover with positive pressure, and had much lower root pressure, and so may be more conservative in closing stomates to prevent permanent hydraulic damage. Interestingly, B. blakaeana did show some ability to regain lost leaf hydraulic conductance, as long as it did not result from embolism formation. Therefore, the conservative stomatal control in this species may be an adaptation to prevent embolism formation.

Figure 6. Fitted relationships of the decline in $K_{\text {leaf }}$ (solid black line), change in optical properties suggesting embolism formation (dotted grey line), and leaf turgor loss point ( $\Psi_{\mathrm{TLP}}$ ) of B. blakeana ('a') and B. vulgaris ('b’). $\Psi_{\mathrm{TLP}}$ of both species occurs prior to any embolism formation and, for B. blakeana, $\Psi_{\text {TLP }}$ also occurs prior to any loss of $K_{\text {leaf }}$. However, B. blakeana maintains turgor until $~ 50 \%$ loss of $K_{\text {leaf. }}$
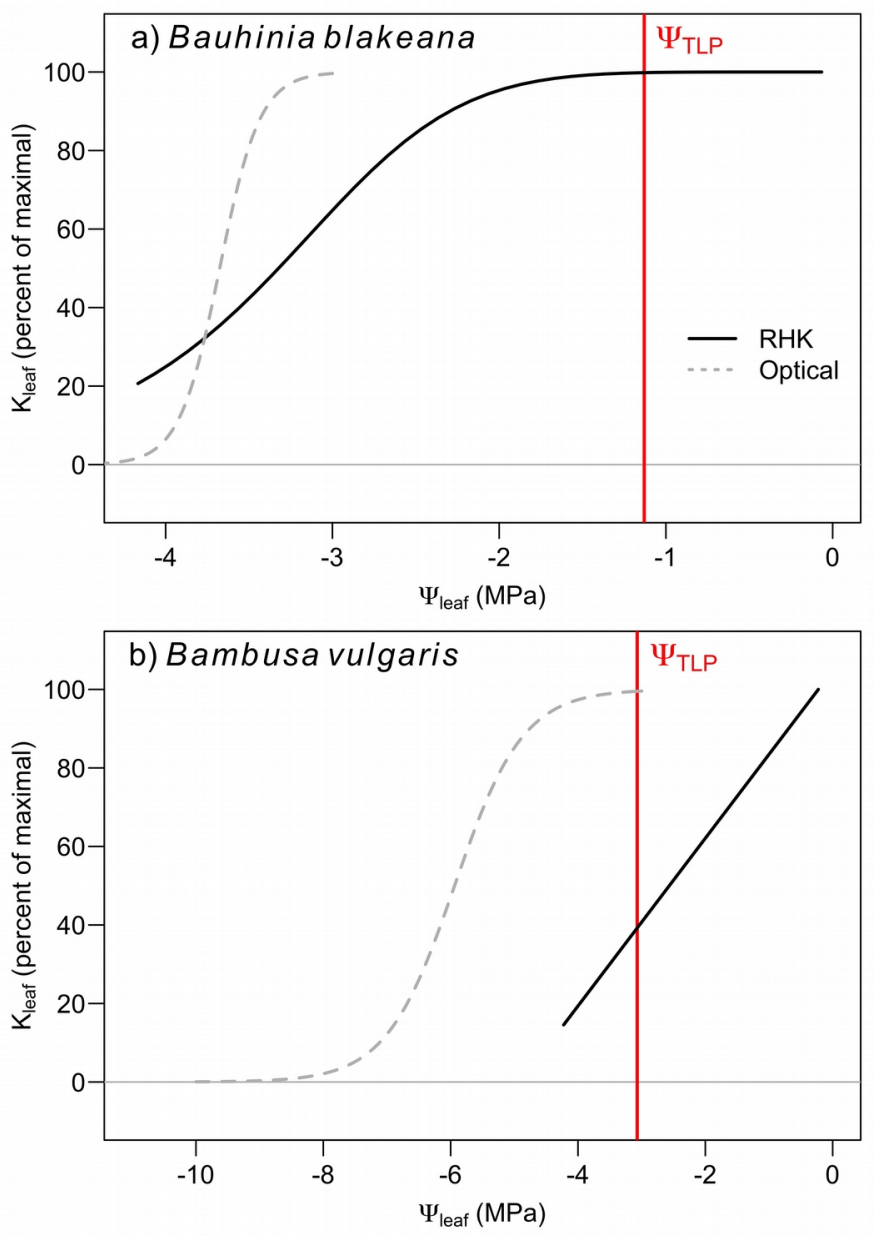


\section{Possible mechanisms for the decline and recovery of $K_{\text {leaf }}$ using the optical method}

Decline in light transmission through individual leaf veins could be clearly observed in both species, though occurring at different values of $\boldsymbol{\Psi}_{\text {leaf. }}$. Assuming that this decline in light transmission is indeed related to the sudden gas-filling of vessels, we can then conclude that no appreciable embolism occurs in either species above ca -3.5 MPa, and therefore cannot be responsible for the initial loss of $K_{\text {leaf }}$ that was measured using RKM. Recovery of embolism (ie. refilling) in the monocotyledon B. vulgaris was observed under positive pressure (red arrows in Figure 4e-h, video link: https://www.youtube.com/watch?v=pZbw4NVcoI0), but recovery was confined to veins near the leaf midrib, which were also the last veins to embolize during dry-down (Figure 3e-h). It is possible that because these veins had experienced embolism only shortly before positive-pressure was applied, they were more prone to embolism reversal than veins located further from the midrib. It is unlikely that veins located further from the midrib would have also recovered from embolism if given a longer rehydration time because embolism in these veins continued to accumulate even during rehydration (Figure 4e-h). Considering both the lack of $K_{\text {leaf }}$ recovery as measured with the RKM (in which no positive pressure was applied during rehydration), as well as the observed recovery of embolism following positive-pressure rehydration, it is possible that $B$. vulgaris requires positive root pressure to regain conductance and also to reverse embolization. Although the mechanism driving declines in $K_{\text {leaf }}$ of Sinarundinaria nitida, another bamboo, was not identified, recovery of mid-day depressions in $K_{\text {leaf }}$ and stomatal conductance were attributed to the generation of positive root pressure (c. $60 \mathrm{kPa}$ ) at night in this species (Yang et al., 2012). In contrast, out results suggest that the physiology of B. blakeana may be coordinated to facilitate the recovery of leaf conductance in the absence of root pressure based on the RKM results, with the important caveat that embolization is likely irreversible in this species, even in the presence of root pressure.

Although we did not observe recovery from embolism formation in the dicotyledon B. blakeana under atmospheric or positive pressure, the positive pressure rehydration treatment appeared to have caused the leakage of cytoplasm/water from either the vessels or mesophyll cells, presumably into either the apoplast or air spaces within the leaf (blue arrow in Figure 4d, video link: https://www.youtube.com/watch?v=0xiCk_0rUaU). The apparent leakage was confined to areas where embolism was not observed during the dry-down phase (Figure 3a-d), which is important for several reasons. First, the absence of leakage adjacent to embolized cells suggests that no water was flowing through these areas and refilling could not occur. But, because embolisms formed in higher order veins first, water could move through the basal portion of the vein, but was then forced out of the vasculature at the point it encountered an embolism. Second, these results support the validity of the optical method of detecting embolisms. The theory of this method is based on the idea that changes in the light-transmittance is caused by a change from liquid to air filled vessels, and since the only places we observed the leakage (which would require a supply of water) were the areas where embolisms were not identified by this method. And third, the leakage suggests that the dry-down resulted in significant membrane damage at water potentials above that required for embolism to occur. Therefore, the point of embolism formation in this species likely occurred after the cells were already damaged beyond recovery. It is also possible that this membrane damage was, at least partially, responsible for the initial decline in $K_{\text {leaf }}$ in this species.

The apparent leakage of cell contents that was observed in the dicotyledon B. blakeana (Figure 5) was not 
observed in the monocotyledon B. vulgaris, even after $\Psi_{\text {leaf }}$ had declined well below the turgor loss point (Figure 4eh). Bamboo possesses stiff cell walls with a high modulus of elasticity (Table 2) and, therefore, we would expect the cells of this species to be more resistant to expansion and contraction. It is possible that this is why B. vulgaris resisted damage during dehydration, and therefore, that the hydraulic pathway was not compromised during dry-down or during positive pressure rehydration. The elasticity of the cell wall is dynamic and can change in response to drought through the production of expansins (Tenhaken, 2015; Houston et al., 2016) and membrane properties affecting leakage, such as lipid content, can also change in response to drought stress (Zhang et al., 2005). If, however, cell wall elasticity does play a role in membrane stability during periods of cell dehydration, then trade-offs between cell wall function related to stiffness may be important to consider in the recovery of leaves from dehydration stress. For example, if it is true that cell wall flexibility is required for high capacitance, but that cell wall rigidity is required to reduce the risk of cell wall deformation and membrane damage during severe dehydration, there must exist a tradeoff between these two traits (cells cannot be both flexible and rigid at the same time). Given this possible tradeoff, we might therefore expect species with high capacitance (flexible cell walls) to be unable to resist membrane damage at very low xylem water potentials (Lechthaler et al., 2016).

\section{Initial sites of embolism}

Our results suggest that embolism formation in the palmate-veined dicotyledon occurred in $2^{\text {rd }} / 3^{\text {rd }}$ order veins first, followed quickly by the $2^{\text {nd }}$ and $1^{\text {st }}$ order veins. Although this species did not have a single midrib, but had a palmate venation pattern, the primary veins were the last to experience embolism formation. The imaging techniques currently being employed have shown some species to experience embolism in the midrib or petiole first (Brodribb et al., 2016a; Scoffoni et al., 2017), but some species of palms exhibit greater vulnerability to embolism in higher order veins (Emilio et al., 2019), and an earlier study using dye on Cercis siliquastrum reported embolism in the higher order veins first (Nardini et al., 2003). Similar to the dicotyledonous plant, the monocot leaves exhibited cavitation in the veins near the leaf margins, while the veins in the midrib and central region of the leaves remained water-filled. Unfortunately, we are unaware of any other data on the order of embolism formation among the veins of monocot leaves with which to compare our results.

Cavitation in the leaf, petiole, or midrib has been suggested as a mechanism to provide segmentation of the plant; isolating embolism to the more distal organs and thus reducing whole-plant water loss (Zimmermann, 1983; Pivovaroff et al., 2014; Nolf et al., 2015; Charrier et al., 2016; Johnson et al., 2016). Whereas cavitation in the petiole is likely to lead to loss of the entire leaf, embolism in the higher order veins could leave part of the venation system of leaves intact and functioning. Alternatively, embolism in the distal veins, which are most closely linked with the supply of water to stomates, might be detrimental for a species that cannot refill these conduits. There appears to be no convincing argument for why we should expect embolization to initiate in the same location within the leaf vasculature across all species and habitats. Rather, it is likely that as we search across a wider set of species, we may find variation in the ranking of vein orders to embolism vulnerability. Therefore, investigating the potential ecological correlates with vein order vulnerability may provide a more satisfying answer to this question than assuming a general pattern across species. 


\section{Conclusion}

There is now much evidence supporting the argument that sources of resistance other than embolism contribute meaningfully to the loss and recovery of $K_{\text {leaf }}$. It is clear from our data, that appreciable loss of $K_{\text {leaf }}$ Occurs before the occurrence of embolism in the two species studied here. Identification of the casual mechanisms underpinning variation in $K_{\text {leaf }}$ is critical for understanding drought tolerance strategies among wild species, as well as the improvement of agricultural species. Considering this, the differences in recovery of $K_{\text {leaf }}$ (measured with RKM) we observed are intriguing but limited in the number of replicates measured. Therefore, we suggest that research of the possible proximate causes of $K_{\text {leaf }}$ decline and the mechanisms of recovery should be a priority for both ecological and agricultural sciences.

\section{Acknowledgements}

This study was co-funded by a visiting fellowship of the Guangxi Department for Foreign Expert Affairs to S.M.G. (2017035) and a grant (31470469) of National Natural Science Foundation to K-F. C..

\section{References}

Bennett J., 1999. Autolt: A freeware BASIC-like scripting language designed for automating the Windows GUI and general scripting.

Blackman C.J, Brodribb T.J, Jordan G.J., 2010. Leaf hydraulic vulnerability is related to conduit dimensions and drought resistance across a diverse range of woody angiosperms. New Phytologist 188: 1113-1123. doi:10.1111/j.14698137.2010.03439.x

Brodersen C.R., Knipfer T., McElrone A.J., 2018. In vivo visualization of the final stages of xylem vessel refilling in grapevine (Vitis vinifera) stems. New Phytologist 217: 117-126. doi:10.1111/nph.14811

Brodribb T.J., Bienaimé D., Marmottant P., 2016a. Revealing catastrophic failure of leaf networks under stress. Proceedings of the National Academy of Sciences 113: 201522569. doi:10.1073/pnas.1522569113

Brodribb T.J., Holbrook N.M., 2003. Stomatal closure during leaf dehydration, correlation with other leaf physiological traits. Plant Physiology 132: 2166-2173. doi:10.1104/pp.103.023879

Brodribb T.J, Skelton R.P., Mcadam S.A.M., Bienaimé D., Lucani C.J., Marmottant P., 2016b. Visual quantification of embolism reveals leaf vulnerability to hydraulic failure. New Phytologist 209: 1403-1409. doi.org/10.1111/nph.13846

Cao K.F., Yang S.J., Zhang Y.J., Brodribb T.J., 2012a. The maximum height of grasses is determined by roots. Ecology Letters 15: 666-672. doi:10.1111/j.1461-0248.2012.01783.x

Charrier G., Torres-Ruiz J.M., Badel E., Burlett R., Choat B., Cochard H., Delmas C.E.L., Domec J-C., Jansen S., King A., Lenoir N., Martin-StPaul N., Gambetta G.A., Delzon S., 2016. Evidence for hydraulic vulnerability segmentation and lack of xylem refilling under tension. Plant Physiology 172: 1657-1668. doi:10.1104/pp.16.01079

Choat B., Brodersen C.R., McElrone A.J., 2015. Synchrotron X-ray microtomography of xylem embolism in Sequoia sempervirens saplings during cycles of drought and recovery. New Phytologist 205: 1095-1105. doi:10.1111/nph.13110

Clearwater M.J., Blattmann P., Luo Z., Lowe R.G., 2007. Control of scion vigour by kiwifruit rootstocks is correlated with spring root pressure phenology. Journal of Experimental Botany 58: 1741-1751. doi:10.1093/jxb/erm029

Cochard H., Delzon S., 2013. Hydraulic failure and repair are not routine in trees. Annals of Forest Science 70: 659-661. doi:10.1007/s13595-013-0317-5

Cochard H., Froux F., Mayr S., Coutand C., 2004. Xylem Wall Collapse in Water-Stressed Pine Needles. Plant Physiology 134: 401-408. doi:10.1104/pp.103.028357

Cochard H., Venisse J-S., Barigah T.S., Brunel N., Herbette S., Guilliot A., Tyree M.T., Sakr S., 2007. Putative role of aquaporins in variable hydraulic conductance of leaves in response to light. Plant Physiology 143: 122-133. doi:10.1104/pp.106.090092

Cowan I.R., Farquhar G., 1977. Stomatal function in relation to leaf metabolism and environment: stomatal function in the regulation of gas exchange. In: Jennings DH, ed. Integration of activity in the higher plant. Cambridge: Cambridge University Press, 471-505.

Emilio T., Lamarque L.J., Torres-Ruiz J.M., King A., Charrier G., Burlett R., Conejero M., Rudall P.J., Baker W.J., Delzon S., 2019. Embolism resistance in petioles and leaflets of palms. Annals of Botany: 1173-1183. doi:10.1093/aob/mcz104 


\section{Journal of

Enns L.C., Canny M.J., McCully M.E., 2000. An investigation of the role of solutes in the xylem sap and in the xylem parenchyma as the source of root pressure. Protoplasma 211: 183-197. doi:10.1007/BF01304486

Fischer M., Kaldenhoff R., 2008. On the pH regulation of plant aquaporins. Journal of Biological Chemistry 283: $33889-33892$. doi:10.1074/jbc.M803865200

Fisher J.B., Guillermo Angeles A., Ewers F.W., López-Portillo J., 1997. Survey of root pressure in tropical vines and woody species. International Journal of Plant Sciences 158: 44-50. doi:10.1086/297412

Givnish T.J., 1986. Optimal stomatal conductance, allocation of energy between leaves and roots, and the marginal cost of transpiration. In: Givnish TJ, ed. On the economy of plant form and function. Cambridge: Cambridge University Press, 171-213.

Gleason S.M., Wiggans D.R., Bliss C.A., Young J.S., Cooper M., Willi K.R., Comas L.H., 2017. Embolized stems recover overnight in Zea mays: The role of soil water, root pressure, and nighttime transpiration. Frontiers in Plant Science 8: 1-11. doi:10.3389/fpls.2017.00662

Hacke U., Sauter J.J., 1996. Xylem dysfunction during winter and recovery of hydraulic conductivity in diffuse-porous and ringporous trees. Oecologia 105: 435-439. doi:10.1007/BF00330005

Johnson D.M., McCulloh K.A., Woodruff D.R., Meinzer F.C., 2012. Evidence for xylem embolism as a primary factor in dehydration-induced declines in leaf hydraulic conductance. Plant, Cell \& Environment 35: 760-769. doi:10.1111/j.13653040.2011.02449.x

Johnson D.M., Wortemann R., McCulloh K.A., Jordan-Meille L., Ward E., Warren J.M., Palmroth S., Domec J-C., 2016. A test of the hydraulic vulnerability segmentation hypothesis in angiosperm and conifer tree species. Tree Physiology 36: 983-993. doi:10.1093/treephys/tpw031

Kim Y.X., Steudle E., 2009. Gating of aqùaporins by light and reactive oxygen species in leaf parenchyma cells of the midrib of Zea mays. Journal of Experimental Botany 60: 547-556. doi:10.1093/jxb/ern299

Knipfer T., Cuneo I.F., Brodersen C.R., McElrone A.J., 2016. In situ visualization of the dynamics in xylem embolism formation and removal in the absence of root pressure: a study on excised grapevine stems. Plant Physiology 171: 1024-1036. doi:10.1104/pp.16.00136

Lechthaler S., Robert E.M.R., Tonné N., Prusova A., Gerkema E., Van As H., Koedam N., Windt C.W., 2016. Rhizophoraceae mangrove saplings use hypocotyl and leaf water storage capacity to cope with soil water salinity changes. Frontiers in Plant Science 7: 1-13. doi:10.3389/fpls.2016.00895

Nardini A., Salleo S., Raimondo F., 2003. Changes in leaf hydraulic conductance correlate with leaf vein embolism in Cercis siliquastrum L. Trees - Structure and Function 17: 529-534. doi:10.1007/s00468-003-0265-Z

Nolf M., Creek D., Duursma R., Holtum J., Mayr S., Choat B., 2015. Stem and leaf hydraulic properties are finely coordinated in three tropical rain forest tree species. Plant, Cell \& Environment 38: 2652-2661. doi:10.1111/pce.12581

O'Leary J.W., 1965. Root-pressure exudation in woody plants. Botanical Gazette 126: 108-115. doi:10.1086/336303

Ocheltree T.W., 2017. Videos of dehydration and rehydration of leaves using the Brodribb-Bienaime-Marmottant 'optical' method: https://www.youtube.com/watch?v=pZbw4NVcoI0.

Ocheltree T.W., Nippert J.B., Prasad P.V.V., 2016. A safety vs efficiency trade-off identified in the hydraulic pathway of grass leaves is decoupled from photosynthesis, stomatal conductance and precipitation. New Phytologist 210: 97-107. doi:10.1111/nph.13781

Pickard W.F., 2003. The riddle of root pressure. I. Putting Maxwell's demon to rest. Functional Plant Biology 30: 121-134. doi:10.1071/FP02035

Pivovaroff A.L., Sack L., Santiago L.S., 2014. Coordination of stem and leaf hydraulic conductance in southern California shrubs: a test of the hydraulic segmentation hypothesis. The New phytologist 203: 842-50. doi:10.1111/nph.12850

Salleo S., Lo Gullo M.A., Trifilò P., Nardini A., 2004. New evidence for a role of vessel-associated cells and phloem in the rapid xylem refilling of cavitated stems of Laurus nobilis L. Plant, Cell and Environment 27: 1065-1076. doi:10.1111/j.13653040.2004.01211.x

Savi T., Casolo V., Luglio J., Bertuzzi S., Trifilo' P., Lo Gullo M.A., Nardini A., 2016. Species-specific reversal of stem xylem embolism after a prolonged drought correlates to endpoint concentration of soluble sugars. Plant Physiology and Biochemistry 106: 198-207. doi:10.1016/j.plaphy.2016.04.051

Schneider C.A., Rasband W.W., Eliceiri K.W., 2012. NIH Image to ImageJ: 25 years of image analysis. Nature Methods 9: 671675. doi:10.1038/nmeth.2089

Scoffoni C., Albuquerque C., Brodersen C.R., Townes S.V., John G.P, Cochard H., Buckley T.N., McElrone A.J., Sack L., 2017. Leaf vein xylem conduit diameter influences susceptibility to embolism and hydraulic decline. New Phytologist 213: $1076-1092$. doi:10.1111/nph.14256

Scoffoni C., McKown A.D., Rawls M., Sack L., 2012. Dynamics of leaf hydraulic conductance with water status: quantification and analysis of species differences under steady state. Journal of Experimental Botany 63: 643-658. doi:10.1093/jxb/err270

Scoffoni C., Vuong C., Diep S., Cochard H., Sack L., 2014. Leaf shrinkage with dehydration: coordination with hydraulic vulnerability and drought tolerance. Plant Physiology 164: 1772-1788. doi:10.1104/pp.113.221424 
Stiller V., Lafitte H.R., Sperry J.S., 2003. Hydraulic properties of rice and the response of gas exchange to water stress. Plant Physiology 132: 1698-1706. doi:10.1104/pp.102.019851

De Swaef T., Hanssens J., Cornelis A., Steppe K., 2013. Non-destructive estimation of root pressure using sap flow, stem diameter measurements and mechanistic modelling. Annals of Botany 111: 271-282. doi:10.1093/aob/mcs249

Tibbetts T.J., Ewers F.W., 2000. Root pressure and specific conductivity in temperate lianas: exotic Celastrus orbiculatus (Celastraceae) vs. native Vitis riparia (Vitaceae). American Journal of Botany 87: 1272-1278. doi:10.2307/2656720

Trifiló P., Raimondo F., Savi T., Lo Gullo M.A., Nardini A., 2016. The contribution of vascular and extra-vascular water pathways to drought-induced decline of leaf hydraulic conductance. Journal of Experimental Botany 67: 5029-5039. doi:10.1093/jxb/erw268

Vaadia Y., 1960. Autonomic diurnal fluctuations in rate of exudation and root pressure of decapitated sunflower plants. Physiologia Plantarum 13: 701-717. doi:10.1111/j.1399-3054.1960.tb08092.x

Wegner L.H., 2014. Root pressure and beyond: Energetically uphill water transport into xylem vessels? Journal of Experimental Botany 65: 381-393. doi:10.1093/jxb/ert391

Willmer C., Fricker M., 1996. Stomata (M Black and B Charlwood, Eds.). London: Chapman \& Hall. doi:10.1007/978-94-0110579-8

Yang S.J., Zhang Y.J., Sun M., Goldstein G., Cao K.F., 2012. Recovery of diurnal depression of leaf hydraulic conductance in a subtropical woody bamboo species: Embolism refilling by nocturnal root pressure. Tree Physiology 32: 414-422. doi:10.1093/treephys/tps028

Zhang Y., Rockwell F.E., Graham A.C., Alexander T., Holbrook N.M., 2016. Reversible leaf xylem Collapse : a potential " circuit breaker " against cavitation. Plant Physiology 172: 2261-2274. doi:10.1104/pp.16.01191

Zimmermann M., 1983. Xylem structure and the ascent of sap. Berlin: Springer-Verlag. doi:10.1007/978-3-662-22627-8 